Tropical Journal of Pharmaceutical Research September 2016; 15 (9): 1909-1914

ISSN: $1596-5996$ (print); 1596-9827 (electronic)

(C) Pharmacotherapy Group, Faculty of Pharmacy, University of Benin, Benin City, 300001 Nigeria.

All rights reserved.

Available online at http://www.tjpr.org

Original Research Article

http://dx.doi.org/10.4314/tjpr.v15i9.14

\title{
Oral thearubigins do not protect against acetaminophen- induced hepatotoxicity in mice
}

\author{
Hussam AS Murad ${ }^{1,2 *}$, Hamid SA Habib ${ }^{3}$, Yasser M Kamel ${ }^{4,5}$, Salah A Alsayed ${ }^{6}$, \\ Soad S Ali ${ }^{7}$, Zohair G Gazzaz \\ ${ }^{1}$ Department of Pharmacology, Faculty of Medicine, Rabigh, King Abdulaziz University, Jeddah, Saudi Arabia, ${ }^{2}$ Department of \\ Pharmacology, Faculty of Medicine, Ain Shams University, Cairo, Egypt, ${ }^{3}$ Department of Pediatrics, Faculty of Medicine, King \\ Abdulaziz University, Jeddah, Saudi Arabia, ${ }^{4}$ Department of Microbiology, Faculty of Medicine, Rabigh, King Abdulaziz \\ University, Jeddah, Saudi Arabia, ${ }^{5}$ Department of Microbiology, Desert Research Center, Cairo, Egypt, ${ }^{6}$ Department of \\ Physiology, Faculty of Medicine, Rabigh, King Abdulaziz University, ${ }^{7}$ Department of Anatomy and Histology, Faculty of \\ Medicine, King Abdulaziz University, Jeddah, Saudi Arabia, ${ }^{8}$ Department of Medicine, Faculty of Medicine, Rabigh, King \\ Abdulaziz University, Jeddah, Saudi Arabia
}

*For correspondence: Email: muradha2000@yahoo.com; Tel: 00966541541341; Fax: 00966024223031

\begin{abstract}
Purpose: To investigate the potential protective effect of oral repeated doses of thearubigins against acetaminophen-induced hepatotoxicity in mice.

Methods: Mice were randomly divided into six groups $(n=8)$ and administered the following: Control group (saline), acetaminophen group (saline), N-acetylcysteine group $(500 \mathrm{mg} / \mathrm{kg} /$ day), and thearubigins groups $(60,70,100 \mathrm{mg} / \mathrm{kg} /$ day). The drugs were given orally by gavage for seven days. On day $7,1 \mathrm{~h}$ after the last dose of treatment, the mice (except control group) were given a single dose of acetaminophen ( $n$-acetyl-p-aminophenol, APAP) orally by gavage $(350 \mathrm{mg} / \mathrm{kg})$ and then sacrificed $4 \mathrm{~h}$ post-APAP intake. Blood was collected for biochemical measurements and their liver were subjected to biochemical and histopathological assessment.

Results: The acetaminophen group showed significant increases $(p<0.001)$ in serum alanine aminotransferase level, hepatic cytochrome P2E1 level, and serum and hepatic malondialdehyde levels. Moreover it showed significant decrease $(p<0.001)$ in serum and hepatic glutathione levels. Morphologically, the liver sections showed cellular necrosis, vacuolization, and degeneration around the centrilobular veins. Pretreatment with $\mathrm{N}$-acetylcysteine reversed all acetaminophen-induced changes ( $p$ $<0.001$ for all biomarkers except for hepatic MDA $(p=0.014)$ while pretreatment with thearubigins failed to reverse any of them.

Conclusion: Oral repeated doses of thearubigins failed to protect against acetaminophen-induced hepatotoxicity in mice and didn't affect hepatic cytochrome P2E1 level.
\end{abstract}

Keywords: Acetaminophen, Hepatotoxicity, Thearubigins, N-acetylcysteine, Cellular necrosis, Vacuolization, Hepatic cytochrome P2E1

Tropical Journal of Pharmaceutical Research is indexed by Science Citation Index (SciSearch), Scopus, International Pharmaceutical Abstract, Chemical Abstracts, Embase, Index Copernicus, EBSCO, African Index Medicus, JournalSeek, Journal Citation Reports/Science Edition, Directory of Open Access Journals (DOAJ), African Journal Online, Bioline International, Open-J-Gate and Pharmacy Abstracts

\section{INTRODUCTION}

Acetaminophen (APAP) is safe when used in regular doses where nearly $95 \%$ of it is metabolized in the liver by glucuronidation and sulfation to non-toxic metabolites. Only $5 \%$ is oxidized by CYP450 isozymes (mainly CYP2E1) to n-acetyl-p-benzoquinone imine (NAPQI) which is then reduced by glutathione (GSH) and excreted as mercapturic acid [1]. In overdose, acetaminophen causes acute liver failure due to saturation of the sulfation pathway and shifting of 
more APAP to the CYP450 pathway forming excessive NAPQI. This excessively-produced NAPQI severely depletes cellular GSH and covalently binds to cellular proteins with increased formation of free radicals causing mitochondrial damage, cellular necrosis, and organ failure. In addition, the increased production of free radicals causes mucosal injuries, damage of cell membrane, and cell death by attacking cellular lipid constituents leading to activation of lipid peroxidation and increasing malondialdehyde (MDA) levels. Antioxidants and GSH precursors such as $\mathrm{N}$ acetylcysteine (NAC) plays an important role in the treatment of APAP toxicity through antagonizing oxidative stress and promoting tissue regeneration [2-4].

In our recently-published study [5], we found that intraperitoneal single dose thearubigins (TRs); the main phenolic pigment of black tea extract; dose-dependently protected against APAPinduced hepatotoxicity in mice. The effects of toxins and drugs differ according to their route of administration. For example, yessotoxin administered to mice orally was found less toxic than that given by the intraperitoneal route [6]. Also, oral quercetin failed to enhance the antitumor effect of trichostatin $A$ in mice while the intraperitoneally-injected quercetin did [7].

The present study was designed to investigate the potential hepatoprotective effect of oral pretreatment with TRs given to mice for seven days prior to oral administration of APAP on the seventh day.

\section{EXPERIMENTAL}

\section{Preparation of thearubigins (TRs)}

The Black tea extract (BTE) was prepared, its ingredients were determined using high performance liquid chromatography, and aqueous solutions of TRs $(60,70$, and 100 $\mathrm{mg} / \mathrm{kg}$ ) were prepared as previously described $[8,9]$. Briefly, the lyophilized BTE was suspended in water and extracted continuously with chloroform to remove caffeine. The aqueous layer was extracted continuously with ethyl acetate $(2 \times 40 \mathrm{~mL})$ for removing of theaflavins (TFs). Finally, TRs were extracted with n-butanol $(3 \times 40 \mathrm{~mL})$ and evaporated using rotary vacuum evaporator.

\section{Animals and drugs}

Swiss male albino mice (20 - $30 \mathrm{~g}$ ) were obtained and housed in cages at $20-22{ }^{\circ} \mathrm{C}$ room temperature in $12 \mathrm{~h}$ light-dark cycle. Food and water were available ad libitum. All drugs and chemicals were purchased from Sigma-Aldrich Corp. (St. Louis, MO, USA) unless stated otherwise.

\section{Induction of acetaminophen toxicity and treatment groups}

After acclimatization for a week, mice were randomly divided into six groups $(n=8)$ and administered the following: Control group (saline), APAP group (saline), NAC group (500 $\mathrm{mg} / \mathrm{kg} /$ day) [10], and three TRs groups (60, 70, $100 \mathrm{mg} / \mathrm{kg} /$ day) [11]. Drugs were given orally by gavage for seven days. On the 7 th day, $1 \mathrm{~h}$ after the last doses of treatments, all groups (except the control group) were given a single dose of APAP by oral gavage $(350 \mathrm{mg} / \mathrm{kg})$ [10] and then the mice were sacrificed $4 \mathrm{~h}$ post-APAP injection by cervical dislocation under light anesthesia. Blood was collected for biochemical measurements and livers were removed, washed in saline, and used for biochemical measurements and histopathological examination [12].

The protocol of the study was approved by King Abdulaziz University Research Ethics Committee (ref no. 142-15) and adhered to the International Guidelines for the Care and Use of Laboratory Animals [13].

\section{Serum biomarker measurements}

The measurements of serum analytes were done by using commercially available kits for alanine aminotransferase (ALT) (Teco Diagnostics, CA, USA), and malonaldehyde (MDA) and GSH (Cell Biolabs, San Diego, CA, USA) according to the manufacturer's protocol.

\section{Hepatic malonaldehyde (MDA) measurement}

The hepatic MDA was measured by using the OxiSelect ${ }^{\mathrm{TM}}$ TBARS Assay Kit (Cell Biolabs, Inc., CA, USA). Briefly, liver specimens were homogenized in $1.15 \%$ potassium chloride buffer $(1 / 10 \mathrm{w} / \mathrm{v})$ and centrifuged. The $10 \%$ homogenate was mixed with an aqueous solution of thiobarbituric acid (TBA). After heating at 95 ${ }^{\circ} \mathrm{C}$ for $1 \mathrm{~h}$, the produced red pigment was extracted with butanol and absorbance was measured at $532 \mathrm{~nm}$ using a plate reader [14].

\section{Hepatic glutathione (GSH) measurement}

The hepatic GSH was measured using GSH assay kit (Cayman Chemical Company, MI, USA). Briefly, liver specimens were homogenized in $5 \%$ trichloroacetic acid and then 
centrifuged for $30 \mathrm{~min}$ at $4{ }^{\circ} \mathrm{C}$. DTNB $\left(5,5^{\prime}-\right.$ dithiobis 2-nitrobenzoic acid) was added to the supernatant. The assay involved reduction of DTNB to a yellow product by the sulfhydryl (SH) group of the GSH present in the sample. The absorbance was measured at $405 \mathrm{~nm}$ using a plate reader. GSH in the supernatant were quantified using the extinction coefficient of DTNB and normalized to the protein in each sample [15].

\section{Hepatic CYP2E1 measurement}

Hepatic CYP2E1 was measured using CYP2E1 assay ELISA kit (Cusabio, Wuhan, China). Briefly, $100 \mathrm{mg}$ liver tissue was rinsed in $1 \mathrm{X}$ phosphate buffered saline (PBS), homogenized in $1 \mathrm{~mL}$ of $1 \mathrm{X}$ PBS, and stored at $-20^{\circ} \mathrm{C}$. Following two cycles of freezing and thawing (to damage the cell membranes) the homogenate was centrifuged for $5 \mathrm{~min}$ at 5000 at $4{ }^{\circ} \mathrm{C}$. The supernatant was removed and the CYP2E1 level was measured immediately. Briefly, a complex was formed between the CYP2E1 present in the sample and its specific antibody pre-coated on the wells. A biotin-conjugated antibody specific for CYP2E1 was then added followed by addition of the avidin conjugated horseradish peroxidase (HRP). On adding the substrate solution, a color was developed which was measured using a microplate reader at $450 \mathrm{~nm}$ [16].

\section{Histopathological examination}

Liver samples were fixed in $10 \%$ phosphatebuffered formalin, embedded in paraffin, and sectioned at 3-5 $\mu \mathrm{m}$ thickness. Liver sections were stained with hematoxylin and eosin $(\mathrm{HE})$, examined in a light microscope (Olympus, $\mathrm{BH}-2$, Tokyo, Japan), and the lesions were graded as mild, moderate, and severe [17].

\section{Statistical analysis}

Data are given as mean \pm standard error of mean (SEM). Comparison between two groups was made using Student's t-test. One-way analysis of variance (ANOVA) with Tukey's posthoc test was applied for comparison of variance between groups. SPSS version 18.0 software was used in the statistical analysis and $p<0.05$ was considered statistically significant.

\section{RESULTS}

APAP mice showed significant increases in serum ALT, hepatic CYP2E1, and serum and hepatic MDA levels. Moreover, they showed significant decreases in serum and hepatic GSH levels. Morphologically, the liver sections showed cellular necrosis, vacuolization, and degeneration around the centrilobular veins. Pretreatment with NAC $(500 \mathrm{mg} / \mathrm{kg} /$ day by oral gavage for 7 days) reversed the biochemical and histopathological changes induced by oral administration of APAP $(350 \mathrm{mg} / \mathrm{kg})$ on the seventh day while pretreatment with TRs $(60,70,100 \mathrm{mg} / \mathrm{kg} /$ day $)$ in the same schedule failed to reverse these changes (Table 1 and Figure 1).

\section{DISCUSSION}

It is well established that acetaminophen (APAP) overdose in mice causes hepatotoxicity manifested by increases in serum ALT level, hepatic CYP2E1 level, and serum and hepatic MDA levels in addition to decreases in serum and hepatic GSH levels [1,18]. Morphologically, the liver sections showed cellular necrosis, vacuolization, and degeneration around the centrilobular veins.

Table 1: Effects of oral TRs on N-acetyl-p-aminophenol (APAP)-induced changes in serum and hepatic biochemical parameters in mice

\begin{tabular}{|c|c|c|c|c|c|c|}
\hline Treatment & $\begin{array}{l}\text { Serum ALT } \\
(\mathrm{U} / \mathrm{I})\end{array}$ & $\begin{array}{l}\text { Serum MDA } \\
(\mathrm{nmol} / \mathrm{ml})\end{array}$ & $\begin{array}{l}\text { Serum GSH } \\
(\mu \mathrm{mol} / \mathrm{ml})\end{array}$ & $\begin{array}{l}\text { Hepatic } \\
\text { MDA } \\
\text { (nmol/mg) }\end{array}$ & $\begin{array}{l}\text { Hepatic GSH } \\
\text { (nmol/mg) }\end{array}$ & $\begin{array}{l}\text { Hepatic } \\
\text { CYP2E1 } \\
(\mathrm{pg} / \mathrm{g})\end{array}$ \\
\hline Control & $21.13 \pm 1.42$ & $16.85 \pm 1.13$ & $15.61 \pm 0.36$ & $1.10 \pm 0.12$ & $25.40 \pm 0.93$ & $4.15 \pm 0.17$ \\
\hline APAP & $\begin{array}{l}420.13 \pm \\
11.22^{*}\end{array}$ & $90.14 \pm 2.32$ & $3.15 \pm 0.25$ & $2.26 \pm 0.14$ & $7.86 \pm 0.25$ & $47.01 \pm 1.36$ \\
\hline NAC & $\begin{array}{l}196.63 \pm 5.69 \\
*, \#\end{array}$ & $25.10 \pm 1.19^{\wedge}$ & ${ }_{\#}^{13.85} \pm 0.27^{n}$ & $\underset{\#}{1.65 \pm 0.08}$ & $21.59 \pm 0.97^{\wedge}$ & $9.49 \pm 0.85^{\prime \prime \#}$ \\
\hline TRs 60 & $\begin{array}{l}419.63 \pm \\
10.64\end{array}$ & $89.65 \pm 2.48^{\circ}$ & $4.13 \pm 0.28$ & $2.33 \pm 0.14$ & $8.24 \pm 0.26$ & $46.74 \pm 1.71$ \\
\hline TRs 70 & $\begin{array}{l}426.00 \pm \\
10.32\end{array}$ & $91.63 \pm 1.47^{*}$ & $4.36 \pm 0.33^{\star}$ & $2.21 \pm 0.14^{\star}$ & $6.58 \pm 0.30$ * & $45.61 \pm 1.00^{*}$ \\
\hline TRs 100 & $422.63 \pm 8.19$ & $87.30 \pm 2.16$ & $3.91 \pm 0.34$ & $2.50 \pm 0.11$ & $7.60 \pm 0.24$ & $50.26 \pm 1.24$ \\
\hline
\end{tabular}

Data are expressed as mean \pm SEM $(\mathrm{n}=8) .{ }^{*} p<0.05$ vs. control . ${ }^{\#} p<0.05$ vs. APAP (350 mg/kg) \& TRs (pretreatment with $60,70,100 \mathrm{mg} / \mathrm{kg} /$ day for 7 days) 

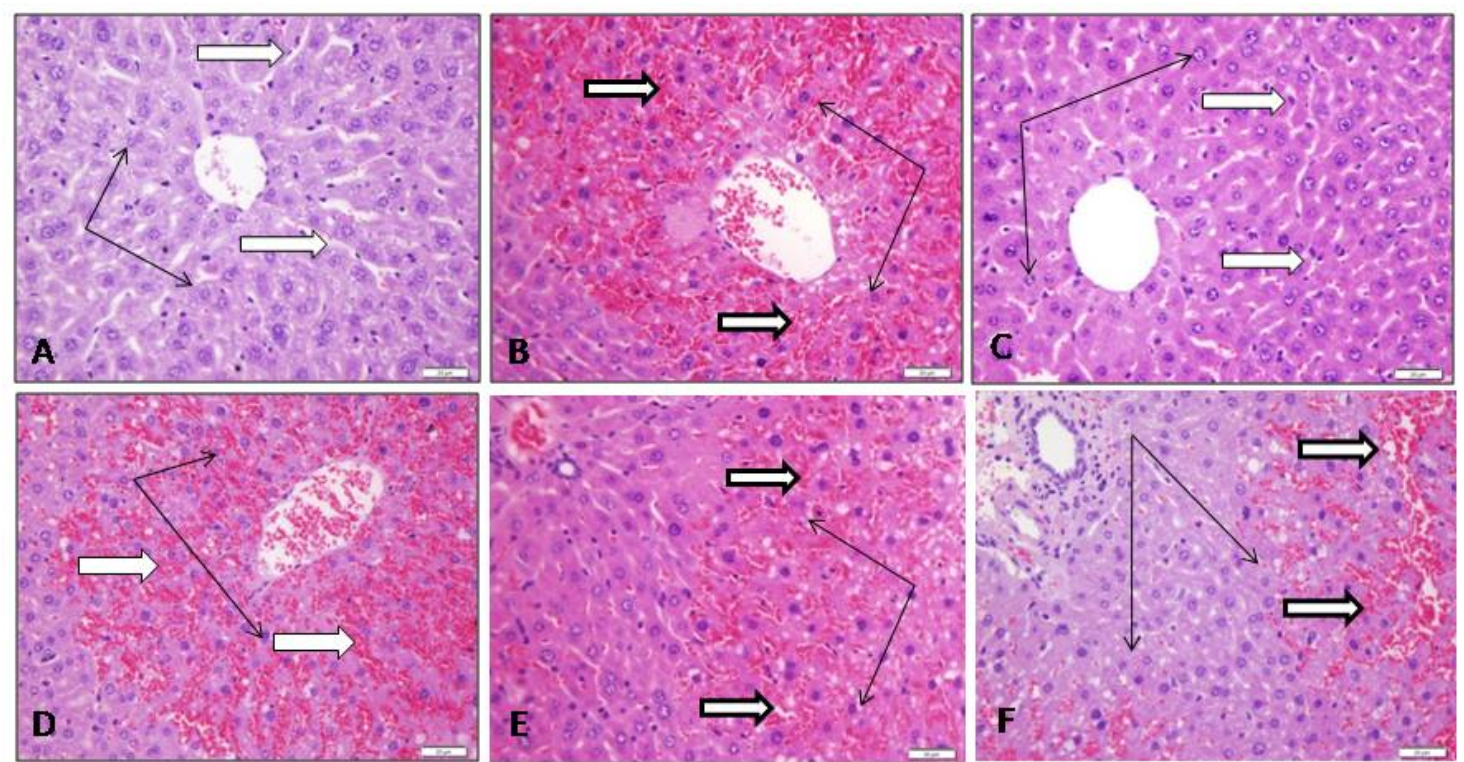

Figure 1: Liver sections (HE, x200) showing effects of pretreatments with TRs on the changes induced by oral administration of APAP in mice. A: control group showing normal central lobular area, normal hepatocyte cell cords (black arrows), and sinusoids (white arrows). B: APAP group showing marked sinusoidal congestion (white arrows) and degeneration of hepatocytes indicated by dark nuclei (black arrows). C: NAC group showing normal liver architecture nearly similar to control group. D, E, and F groups (representing TRs 60, 70 \& 100 groups respectively) show marked sinusoidal congestion (white arrows) around the central vein and degenerated hepatocytes (black arrows) nearly similar to APAP group

NAC protects against APAP overdose in mice and reverses the APAP-induced biochemical and histopathological changes because it replenishes hepatic GSH which scavenges NAPQI, helps rapid recovery of mitochondrial $\mathrm{GSH}$, and scavenges reactive oxygen and nitrogen radicals [19].

In the current study, pretreatment of mice with TRs orally by gavage for 7 days failed to reverse the biochemical and histopathological changes induced by oral administration of APAP in the seventh day. These results contrast with our recently-published findings [5] where posttreatment with TRs by intraperitoneal injection dose-dependently reversed the changes induced by prior intraperitoneal injection of APAP. This discrepancy may be attributed to differences in study design, routes of administration, and in time points at which the outcomes were measured (in the current work mice were sacrificed at $4 \mathrm{~h}$ post-APAP intake while in the previous work mice were sacrificed at $6 \mathrm{~h}$ post-APAP injection).

The mechanisms of APAP-induced hepatotoxicity are complicated and thus on testing a drug for a potentially-protective effect, misinterpretation of the results may occur especially with plant extracts [20]. Perhaps this applies to our studies; the term TRs was introduced since fifty years ago however their exact chemical structure remains undefined up till now [21]. Consequently, no clear data about their pharmacokinetic profiles are available. In addition, there is little research on black tea theaflavins and thearubigins regarding their gastrointestinal absorption, metabolism, and potential impact on health [22]. A similar contrast was reported by Catterall et al $[23,24]$. In the earlier study [23], they found that theafulvins, a fraction of black tea TRs, inhibited the hepatic CYP450 activity associated with the CYP2E subfamilies. However, in the second study [24], they reported that dietary intake of theafulvins for four weeks failed to affect the hepatic CYP450 activity or composition in rats, but downregulated expression and activity of the intestinal CYP 450 enzymes including CYP2E1. They attributed these contradictory results to poor oral bioavailability of the black tea TRs due to poor absorption and/or extensive first pass intestinal elimination by mammalian and microbial enzymes resulting in higher local concentrations of theafulvins in GIT. A green tea polyphenol given daily for four weeks on an empty stomach; to improve its oral bioavailability; failed to affect the human CYP-mediated drug metabolism at any clinically relevant level [25].

In contrast, tea polyphenols (TPs) given for six days prior to paracetamol $(1000 \mathrm{mg} / \mathrm{kg})$ dosedependently suppressed CYP450 expression, 
reduced CYP2E1 and CYP1A2 expression at both protein and mRNA levels, relieved paracetamol-induced hepatic injury, and decreased number of deaths in mice with APAP overdose [26]. Moreover, black tea and its main polyphenols effectively scavenged the free radicals in vitro in mice and thus they increased the superoxide dismutase and glutathione peroxidase activities and decreased the MDA level [27]. Selective inhibitors of CYP2E1 such as 4-methylpyrazole and disulfiram significantly reduced NAPQI production and then they could be useful in treating acetaminophen overdose [16]. Chlorogenic acid (a polyphenolic compound abundant in fruits, vegetables, and some medicinal herbs) relieved acetaminopheninduced liver damage through modest inhibition of CYP2E1 and antioxidant effects [12]. The complex structure of TRs is considered an obstacle facing studies that evaluate their bioavailability and mechanisms of action [28], however such studies are necessary to help explain the different; even contradictory; results obtained with changing their route of administration.

\section{CONCLUSION}

Oral repeated doses of black tea TRs do not protect against acetaminophen-induced hepatotoxicity in mice and don't affect hepatic CYP2E1 activity. These findings contradict our recent findings that indicate dose-dependent protective effect of a single intraperitoneal injection of TRs against acetaminophen-induced hepatotoxicity in mice through their antioxidant effect. This discrepancy may be due to poor GI absorption of TRs, thus a full pharmacokinetic study is recommended.

\section{DECLARATIONS}

\section{Acknowledgement}

This project was funded by Deanship of Scientific Research (DSR), at King Abdulaziz University (KAU), Jeddah, Saudi Arabia (grant no. 168/828/1434). The authors therefore acknowledge with thanks DSR for their technical and financial support. The participation of Nader Multany, Assem Almazmomy, Yossef Rayess, and Abdalellah Alnafea, all of whom are 3rd year medical students of Faculty of Medicine, Rabigh, King Abdulaziz University, is gratefully acknowledged.

\section{Conflict of Interest}

No conflict of interest associated with this work.

\section{Contribution of Authors}

The authors declare that this work was done by the authors named in this article and all liabilities pertaining to claims relating to the content of this article will be borne by them.

\section{REFERENCES}

1. Cheung C, Yu AM, Ward JM, Krausz KW, Akiyama TE, Feigenbaum L, Gonzalez FJ. The cyp2e1-humanized transgenic mouse: role of cyp2e1 in acetaminophen hepatotoxicity. Drug Metab Dispos 2005; 33: 449-457.

2. Hinson JA, Roberts DW, James LP. Mechanisms of acetaminophen-induced liver necrosis. Handb Exp Pharmacol 2010; 196: 369-405.

3. Guo $Q$, Shen Z, Yu $H$, Lu G, Yu Y, Liu X, Zheng $P$. Carnosic acid protects against acetaminophen-induced hepatotoxicity by potentiating Nrf2-mediated antioxidant capacity in mice. Korean J Physiol Pharmacol 2016; 20(1): 15-23.

4. Jaeschke $H$, Bajt ML. Intracellular signaling mechanisms of acetaminophen-induced liver cell death. Toxicol Sci 2006; 89: 31-41.

5. Murad HA, Habib H, Kamel Y, Alsayed S, Shakweer M, Elshal M. Thearubigins protect against acetaminopheninduced hepatic and renal injury in mice: biochemical, histopathological, immunohistochemical, and flow cytometry study. Drug Chem Toxicol 2016; 39(2): 190198.

6. Aune T, Sørby R, Yasumoto T, Ramstad H, Landsverk $T$. Comparison of oral and intraperitoneal toxicity of yessotoxin towards mice. Toxicon 2002; 40(1): 77-82.

7. Chan ST, Lin YC, Chuang $\mathrm{CH}$, Shiau RJ, Liao JW, Yeh $S L$. Oral and intraperitoneal administration of quercetin decreased lymphocyte DNA damage and plasma lipid peroxidation induced by TSA in vivo. Biomed Res Int. 2014; 2014: 580626. 9 pp.

8. Chaudhuri L, Basu S, Seth P, Chaudhuri T, Besra SE, Vedasiromoni JR, Ganguly DK. Prokinetic effect of black tea on gastrointestinal motility. Life Sci 2000; 66(9): 847-854.

9. Murad HA, Abdallah HM. Black Tea Extract and its Thearubigins Relieve the Sildenafil-Induced Delayed Gut Motility in Mice: A Possible Role of Nitric Oxide. Phytother Res 2014; 28(11): 1687-1691.

10. Whitehouse LW, Wong LT, Solomonraj G, Paul CJ, Thomas BH.N-acetylcysteine-induced inhibition of gastric emptying: a mechanism affording protection to mice from the hepatotoxicity of concomitantly administered acetaminophen. Toxicology 1981; 19(2): 113-125.

11. Mehri D, Monsef-Esfahani HR, Gharibzadeh S, Jafari K, Faghihi M. Effects of black tea extract and its thearubigins on whole gut transit time in mice: involvement of 5-HT3 receptors. JJNPP 2008; 3(1): 3944.

Trop J Pharm Res, September 2016; 15(9): 1913 
12. Pang C, Sheng YC, Jiang P, Wei H, Ji LL. Chlorogenic acid prevents acetaminophen-induced liver injury: the involvement of CYP450 metabolic enzymes and some antioxidant signals. J Zhejiang UnivSci B. 2015; 16(7): 602-610.

13. Guide for the care and use of laboratory animals, Eighth edition, 2011. The National Academies Press, Washington, USA. Available from: https://grants.nih.gov/grants/olaw/Guide-for-the-Careand-use-of-laboratory-animals.pdf

14. Ohkawa H, Ohishi N, Yagi K. Assay for lipid peroxides in animal tissues by thiobarbituric acid reaction. Anal Biochem 1979; 95: 351-358.

15. Moron MS, Depierre JW, Mannervik B. Level of glutathione, glutathione reductases and glutathione $S$ transferase activities in rat lung and liver. Biochim Biophys Acta 1979; 582: 67-78.

16. Hazai E, Vereczkey L, Monostory K. Reduction of toxic metabolite formation of acetaminophen. Biochem Biophys Res Commun 2002; 291(4): 1089-1094.

17. Cover C, Mansouri A, Knight TR, Bajt ML, Lemasters JJ, Pessayre D, Jaeschke $H$. Peroxynitrite-induced mitochondrial and endonuclease-mediated nuclear DNA damage in acetaminophen hepatotoxicity. J Pharmacol Exper Therap 2005; 315: 879-887.

18. Lim AY, Segarra I, Chakravarthi S, Akram S, Judson JP. Histopathology and biochemistry analysis of the interaction between sunitinib and paracetamol in mice. BMC Pharmacol 2010 ;10:14. doi: 10.1186/1471-221010-14.

19. James LP, McCullough SS, Lamps LW, Hinson JA. Effect of $\mathrm{N}$-acetylcysteine on acetaminophen toxicity in mice: relationship to reactive nitrogen and cytokine formation. Toxicol Sci 2003; 75(2): 458-467.

20. Jaeschke $H$, Williams CD, McGill MR, Xie $Y$, Ramachandran A. Models of drug-induced liver injury for evaluation of phytotherapeutics and other natural products. Food Chem Toxicol 2013; 55: 279-289.
21. Yassin GH, Koek JH, Kuhnert N. Model system-based mechanistic studies of black tea thearubigin formation. Food Chem 2015; 180: 272-279.

22. Clifford MN, van der Hooft JJ, Crozier A. Human studies on the absorption, distribution, metabolism, and excretion of tea polyphenols. Am J Clin Nutr 2013; 98(6 Suppl): 1619S-1630S.

23. Catterall F, Copeland E, Clifford $M N$, loannides C. Contribution of theafulvins to the antimutagenicity of black tea: their mechanism of action. Mutagenesis 1998; 13(6): 631-636.

24. Catterall F, McArdle NJ, Mitchell L, Papayanni A, Clifford $M N$, loannides $C$. Hepatic and intestinal cytochrome P450 and conjugase activities in rats treated with black tea theafulvins and theaflavins. Food Chem Toxicol 2003; 41(8): 1141-1147.

25. Chow HH, Hakim IA, Vining DR, Crowell JA, Cordova CA, Chew WM, Xu MJ, Hsu CH, Ranger-Moore J, Alberts DS. Effects of repeated green tea catechin administration on human cytochrome P450 activity. Cancer Epidemiol Biomarkers Prev 2006; 15(12): 24732476.

26. Chen $X$, Sun CK, Han GZ, Peng JY, Li Y, Liu YX, Lv YY, Liu KX, Zhou Q, Sun HJ. Protective effect of tea polyphenols against paracetamol-induced hepatotoxicity in mice is significantly correlated with cytochrome P450 suppression. World J Gastroenterol 2009; 15(15): 18291835.

27. Sun S, Pan S, Ling C, Miao A, Pang S, Lai Z, Chen D, Zhao $C$. Free radical scavenging abilities in vitro and antioxidant activities in vivo of black tea and its main polyphenols. J Medic Plant Res 2012; 6(1): 114-121.

28. Wiseman S, Mulder T, Rietveld A. Tea flavonoids: bioavailability in vivo and effects on cell signaling pathways in vitro. Antioxid Redox Signal 2001; 3(6): 1009-10021. 